\title{
Mechanical and Microstructure Properties of Friction Stir Welding Joints of Aluminum Reinforced with Silicon Carbide Nanoparticles
}

\author{
Bassem F. Felemban \\ Department of Mechanical Engineering, College of Engineering, Taif University, Taif 21974, Saudi Arabia. \\ E-mail: b.felemban@tu.edu.sa
}

\begin{abstract}
In this works, specimens of silicon carbide nanoparticles reinforced aluminum composite were welded using Friction Stir Welding (FSW) technique. The principle aim of this study is to exam the effect of using this welding technique on the mechanical properties and the microstructure of this material. The present nanocomposite has been fabricated by using Ultrasonic assisted Stir Casting with a weight ratio $1 \mathrm{wt} . \%$ of $\mathrm{SiC}$ nanoparticles. A vertical milling machine has been adapted to be used in FSW processes. The frictional heat causes the materials to soften quickly, without reaching melting state, and allows the pin to traverse along the welding joint. The working parameters, i.e., rotational speed and tool penetration were taken as constants with two transverse speeds. The results show that FSW technique permits joining, with a significant success, the present nanocomposites. The mechanical properties and microstructure characteristics of the welded joint were experimentally evaluated and discussed.
\end{abstract}

Keywords: Nanocomposite, SiC, Friction Stir Welding, Mechanical properties, Microstructure

\section{INTRODUCTION}

Aluminum alloy reinforced with nanoceramic particles is one of the most recent composite materials with super mechanical and physical properties. Applying these new materials to modern technology requires studying their properties from different angles to maximize their benefits and applications. Of these nanocomposite materials, Al alloy reinforced with nano Silicon Carbide particles ( $\mathrm{SiCp}$ ) is one of the most commonly used in modern industries, considering the cost of manufacturing and superiority of properties [1]. These properties include high thermal conductivity, abrasion resistance, tribology, creep resistance, dimensional stability, and exceptionally good stiffness. As with all composites, aluminum matrix composites are not a single material but a family of materials whose stiffness, strength, density, thermal and electrical properties can be designed and engineered [2].

Kamrani et al [3] studied the effect of volume fraction of the reinforcement on the mechanical properties of $\mathrm{Al}-\mathrm{SiC}$ nanocomposites. The volume fraction of the silicon carbide were ranging between 1 and 10 vol.\%. They found that $\mathrm{Al}$ matrix nanocomposites showed higher strength with increasing the volume fraction of reinforcement. The hard part was the material fabrication process, and the reason was regarding uniform dispersion of nanoparticles in the matrix material [3-5]. By using the silicon carbide reinforced aluminum nanocomposites with various volume fractions, it showed that the yield strength, compressive strength, and hardness are increasing with increasing the volume fraction of the reinforcement [6-8]. The studies focused on the composites material in micro-size, and the weight percentage was one of the factors to change the mechanical properties. Recently, nanocomposite materials have attracted the attention as suitable alternatives to overcome the limitations of applications of the traditional composite materials and monolithic alloys. Although, these new materials face the preparation challenges related to the control of elemental composition and stoichiometry in the nano-cluster phase, they offer better mechanical, thermal and tribological properties over the micro-composites. Recent researches have also found that nano-sized reinforcement particles increase strength, ductility and toughness [8,9].

On the other side, Friction Stir Welding (FSW) technology is an advanced technique in metals' welding, as it has many technical and environmental advantages [10]. It has the advantages of energy efficient process, environmentally friendly, welding similar and dissimilar alloys and welding the non-weldable alloys [11,12]. FSW involves plastic deformation and welding of the alloys, but at a temperature below the melting point. The combination of heat generated by friction and consequent plastic deformation are the main causes of metal softening [13]. FSW has shown considerable potential for welding what were considered difficult-to-weld. This process is a semi-solid state welding and using the friction for heating the joint. Several advantages are found out in this welding process of the so called "unweldable or difficult to be welded" materials, such as some of Al alloys, with respect to the traditional welding processes, since no melting is reached [14.15]. It became very common knowledge that when applying this welding technique that the welding section is divided into four regions distinct from each other, as shown in Fig. 1, namely: A) base metal, B) heat affected zone (HAZ), C) thermo-mechanically affected zone (TMAZ), and D) weld nugget $[10,16]$.

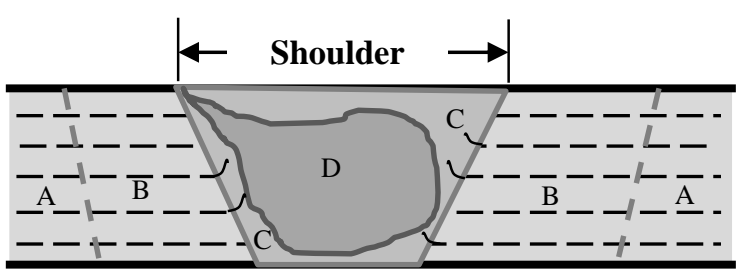

Fig. 1 Schematic draw of a common FSW weld crosssection 
The present paper aims at welding small specimens of nanoSiCp composite materials using FSW process by employing an end-mill machine tool. Some of the mechanical properties will be measured to investigate the quality of the welded joints. Microscopic investigations will be made, using optical and scanning electron microscopes (SEM), to examine the weld microstructure in order to find out the dominated mechanisms that may play a role in strengthening the joints.

\section{EXPERIMENTAL WORK}

\section{A. Material}

The material used in this work is Al-SiC nanocomposite materials, with $1 \%$ weight percent of the reinforcement nanoparticles. This nanocomposite material was purchased from NANOSHEL LLC, Wilmington DE, USA and it was fabricated by casting technique [17-19]. Weight percentage of added nanoparticles is considered a key factor in improving the mechanical properties of nanocomposites, and some researchers have employed different values ranging between $1 \%$ and 10 vol. $\%$ [3,7]. The chemical composition of base alloy as has been received from the manufacturer was, $0.21 \% \mathrm{Fe}, 0.15 \% \mathrm{Si}, 0.04 \% \mathrm{Sn}, 0.03 \% \mathrm{Ti}, 0.02 \% \mathrm{~Pb}, 0.02 \% \mathrm{Ni}$, and the balance is $\mathrm{Al}$ [20]. Reinforcement of this alloy with nano $\mathrm{SiC}$ particles makes it a good candidate for using in aircraft structural parts and other structural applications where very high strength and good resistance to corrosion are required. The specimens used in this work were received in shape small plates with dimensions $4 \times 15 \times 30 \mathrm{~mm}$. The main part of this work is welding of specimens of nanocomposites using FSW technique and then measuring the mechanical properties and examining the microstructure of the weld joints [21].

\section{B. FSW's Tool and Process}

In this work, a vertical milling machine has been adapted to be used in FSW processes. A special tool was designed and fabricated from an alloy steel and then was fitted on a special tool holder. The tool and its holder have been assembled and then put in place of the end mill tool. The FSW tool is usually characterized by a specific geometry in order to limit the contact between tool shoulder and specimen, see Table 1 $[10,14]$. Fig. 2 shows a typical FSW being undertaken with the material rigidly restrained and fixed at the end mill machine table. Prior starting welding, the specimens have been rigidly fixed with the faces to be welded abutted to each other. The FSW process, here, involves piercing a hole at the starting point of the joint with a rotating steel pin. Once the tool penetrates the work piece, the friction caused by the rotating tool and shoulder resulted in frictional heating and plasticization of the surrounding material. The pin continues, stationary, rotates and the specimen moves forward in the direction of welding $[22,23]$. The tool is then moved along the joint, when welding this nanocomposite, employed rotation speeds of $1250 \mathrm{rpm}$ and two transverse speeds of 25 and $30 \mathrm{~mm} / \mathrm{min}$. All the specimens were subjected to a constant force of $\sim 10 \mathrm{KN}$. More details regarding FSW tool geometry and welding conditions are in Table 1. As the tool start forming the joint, the material is heated and plasticized by the leading edge of the tool and transported to the trailing face of the pin, where, upon consolidation, it forms a solid-phase weld [1,15,23].

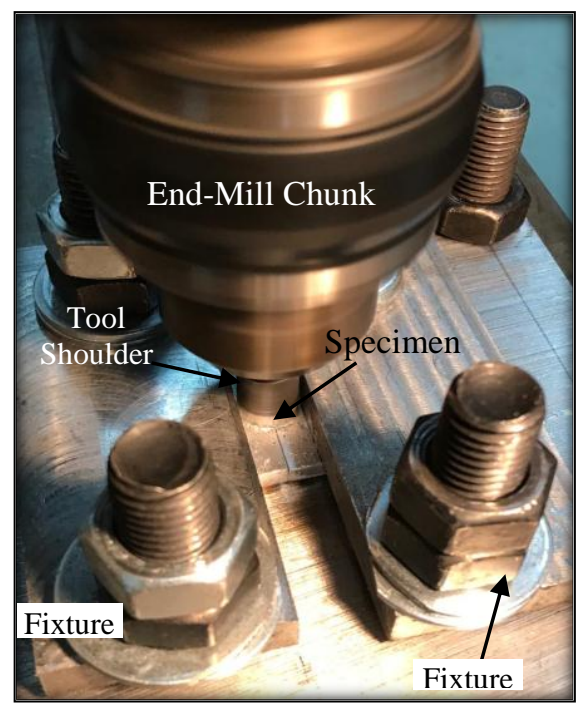

Fig. 2: Typical image of FSW process

Table 1. Welding conditions and geometry of tool pin and shoulder.

\begin{tabular}{c|c|c|c|c|c|c}
\hline $\begin{array}{c}\text { Pin } \\
\text { shape }\end{array}$ & $\begin{array}{c}\text { Pin } \\
\text { length, } \\
\mathrm{mm}\end{array}$ & $\begin{array}{c}\text { Thread } \\
\text { diameter, } \\
\mathrm{mm}\end{array}$ & $\begin{array}{c}\text { Tilt } \\
\text { angle }\end{array}$ & $\begin{array}{c}\text { Shoulder } \\
\text { diameter, } \\
\mathrm{mm}\end{array}$ & $\begin{array}{c}\text { Rotational } \\
\text { speed, rpm }\end{array}$ & $\begin{array}{c}\text { Transverse } \\
\text { speed, } \\
\mathrm{mm} / \mathrm{min} .\end{array}$ \\
\hline Thread & 3.7 & 4 & $3^{\circ}$ & 10 & 1250 & 25,30 \\
\hline
\end{tabular}

\section{Microhardness and Microstructure Examinations}

The quality of FSW joints were investigated by measuring the microhardness and examining microstructure of the specimens. Mirohardness testing was undertaken using Vickers hardness tester, in accordance with ASTM E384. Measurement was made at positions on the traverse cross-section of the welded joint with a step of $\sim 1.5-2 \mathrm{~mm}$ and applying a load of $50 \mathrm{~N}$ for duration time of 10 to 15 second. Each point on the curve represents at least the average of three measurements of microhardness to ensure the credibility of the results. In an preparation microstructure investigations, some of the specimens were etched using Keller's reagent (water solution containing (vol.) $2.5 \% \mathrm{HN} 3,1.5 \% \mathrm{HCI}$ and $0.5 \% \mathrm{HF}$ ). The microstructure of FSW joints was also examined by using optical and scanning electron microscopes (SEM).

\section{RESULTS AND DISCUSSIONS}

The results of microhardness testing and microstructure investigation of FSW joints of $\mathrm{Al}-\mathrm{SiC}$ nanocomposite specimens are presented in the following sections.

\section{A. FSW specimens}

Welds with good quality have been achieved by FSW process as, where the front and back faces of a welded sample can be seen in Fig. 3. Visual inspection of the samples shows the success of this technique in welding samples of the present nanocomposite material. Further investigations of the microstructure and the properties of material will be carried out to examine the weld joints with satisfaction quality. As is evident, the surface defects are minimal and the bonding strength and cohesion between the two pieces of the weld specimen are high. 

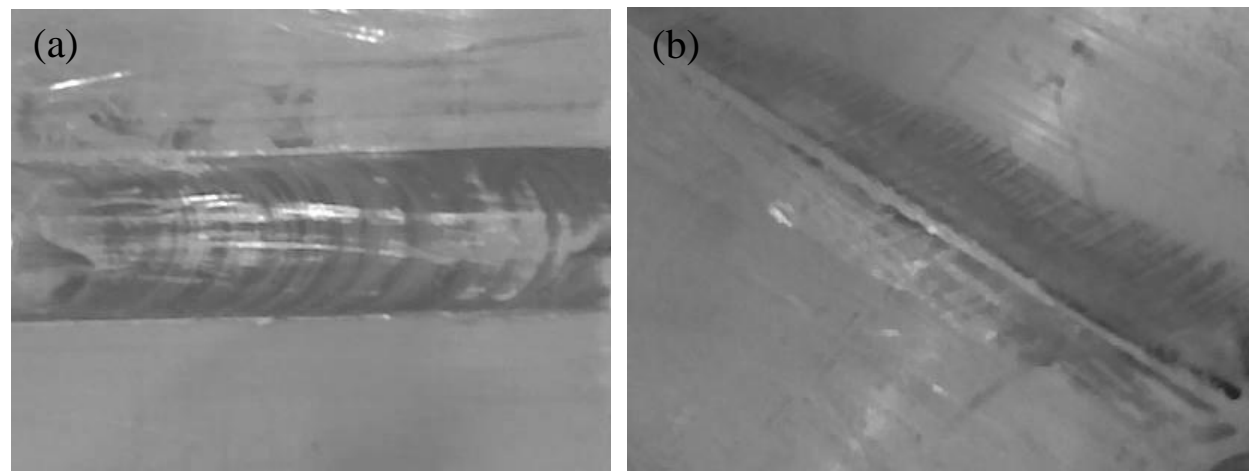

Fig. 3: Appearance of the as-weld nanocomposite sample; a) upper surface, and b) bottom face; welding conditions: weld speed, $1250 \mathrm{rpm}$ and transverse speed, $30 \mathrm{~mm} / \mathrm{min}$.

\section{B. Microhardness of FSW Specimens}

The microhardness of welded samples was measured along the transverse section perpendicular to the weld direction for two different transverse speeds; 30 and $25 \mathrm{~mm} / \mathrm{min}$. The measurement started from the base material in one side, with about $1.5-2 \mathrm{~mm}$ step up to the center of the weld passing to the other side of the weld joint. Fig. 4 shows that the microhardness value at the center of weld is the highest for the used transverse speeds and that the hardness value at the base material is the lowest compared to the rest of the other points. Slight difference between both cases is observed. It is obvious that the highest the transverse speed the highest the microhardness. Frictional heat was created between the wear resistant pin and the two pieces of the nanocomposites specimens that were butted together and clamped by a backing pad. This frictional heat leads to generate residual stresses in the welding zone in varying proportions, which increase the hardness value in these regions [10].

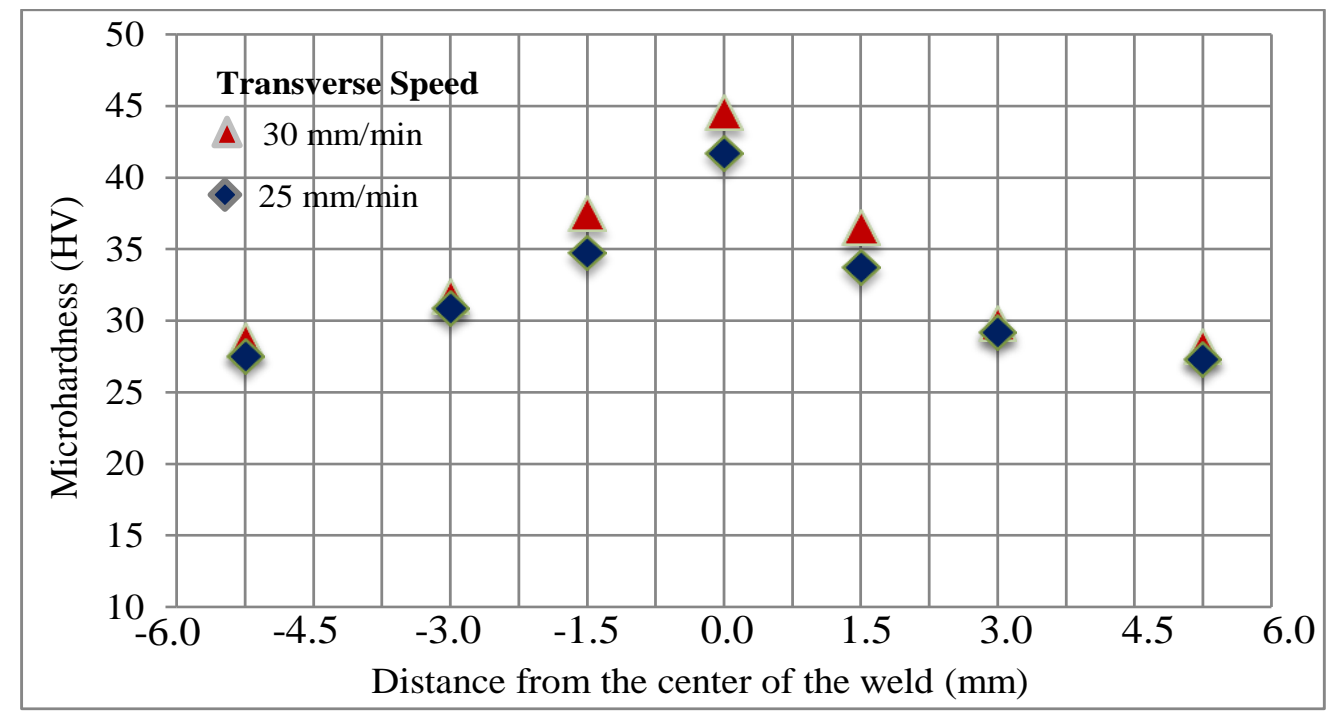

Fig. 4: Microhardness of FSW nanocomposite specimens versus distance from weld center.

As has been mentioned previously, the weld zones are basically divided into four regions. These regions are; base metal, heat affected zone (HAZ), thermo-mechanically affected zone (TMAZ) and weld nugget. The greatest strength recovery occurs in the weld nugget. Softening occurs in the HAZ with a significant drop in microhardness as the TMAZ is approached [11]. Both coarsening and dissolution lead to a drop in hardness, but full strength recovery only occurs following dissolution which is not happened. Another observation related to FSW tool, its direction of rotation and progress during welding process is that the microhardness of the retreating side is slightly higher than that of the advancing side.

\section{Microstructure of FSW Specimens}

Fig. 5 shows the microstructure of four distinct images of a specimen welded using FSW technique, each one was captured from a specific region of the weld cross-section with same magnification, X200. As shown in Fig. 5.a which represents the base material, it has large, equiaxial and homogeneous grains. It is evident from the figure that the nanoparticles are uniformly distributed on the grains boundaries of the $\mathrm{Al}$ matrix. While in Fig. 5.b, which represents HAZ, elongated grains with smaller size compared with those in Fig. 5.a are observed. In addition, the distribution of nanoparticles has slightly modified. Smaller and elongated grains more than observed in the previous region can be seen in Fig. 5.c, which represents TMAZ region. The 
International Journal of Engineering Research and Technology. ISSN 0974-3154, Volume 13, Number 10 (2020), pp. $2973-2978$

(C) International Research Publication House. https://dx.doi.org/10.37624/IJERT/13.10.2020.2973-2978

microstructure of the weld nugget shows smaller, uniformly distributed and equiaxed grains as shown in Figure 5.d. Further distribution of the nanoparticles can be seen at the grain boundaries, represented by the dark portions in the image.
These finding can be clearly seen in the results obtained from examining the microstructure of transverse cross-section of FSW specimen using SEM shown in Figs. 6.

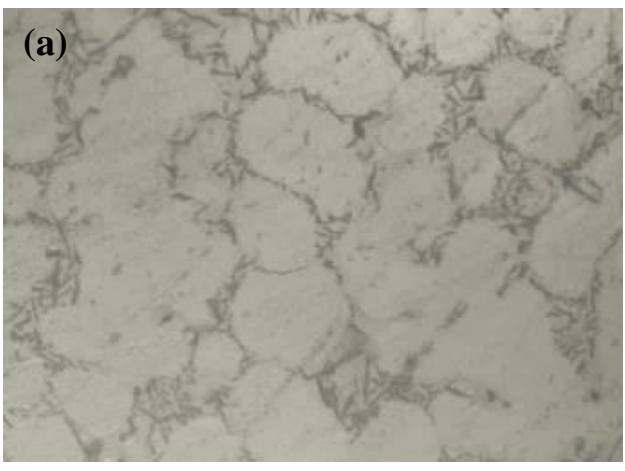

(c)

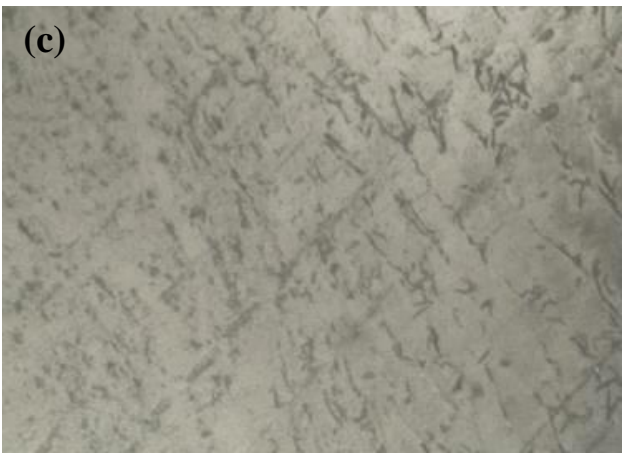



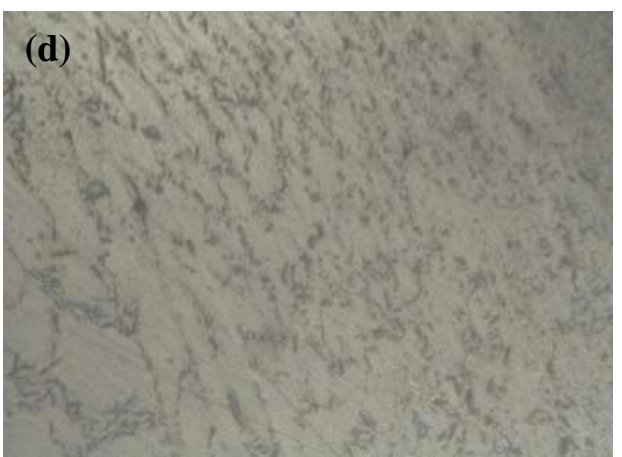

Fig. 5: Optical images of FSW of etched nanocomposite specimen, X200; a) Base metal: large and equiaxial grains, b) HAZ: large and elongated grains, c) TMAZ: small and elongated grains, and d) weld nugget, small and homogenously distributed grains.
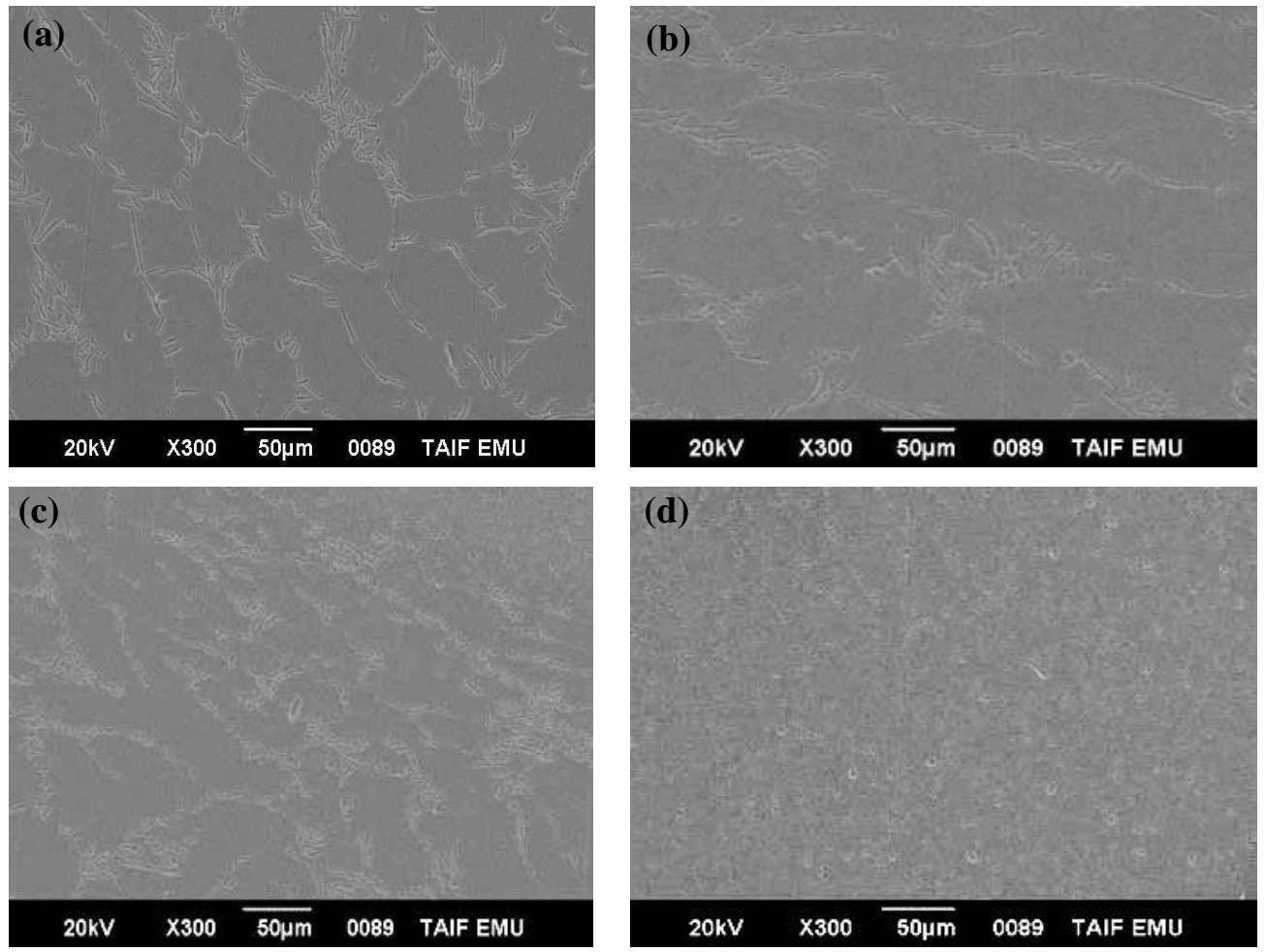

Fig. 6: SEM images of etched FSW of nanocomposite specimen, X300; a) Base metal, b) HAZ, c) TMAZ, and d) weld nugget 
In an explanation of these results, initially the material is extruded at the surface, but as the tool shoulder contacts the upper face of the specimens, the deformed material is compressed between the shoulder, parent material and backing plate. It was found that the main contributor to the frictional heat is the tool shoulder once the tool has penetrated the material [15,23]. Pressure provided by the shoulder forces plastic-like material to the rear of the pin where it consolidates and cools to form a bond. The bond is not actually made of plastic, but it shows many plastic-like properties, making the bond incredibly strong without damaging the original material [24]. In this way, the mechanical characteristics are locally decreased and the blanks material reaches a sort of "soft" state; no melting is observed, a circumferential metal flow is obtained all around the tool pin and close to the tool shoulder contact surface. As such material softening is obtained; the tool can be moved along the joint avoiding the pin fracture due to excessive material reaction $[1,12]$. The mechanical properties and low distortion of the welded zone have been attributed to the low heat input and absence of melting. This is observed due to the localized strain formation during hardness measurement of the welded zones. It turned out that the increase in hardness has to be related to the more homogeneous strain distribution in the welding region and heat affected zone.

\section{CONCLUSIONS}

Specimens of aluminum reinforced with 1 wt.\% SiC nanoparticles composite were welded using FSW process with satisfactory quality. The microhardness and the microstructure of the weld joints was examined and we came up with the following conclusions:

- The repeatable quality of the welds can improve existing products and may lead to a number of new product design previously not possible.

- The results showed that the microhardness values of the center of weld is the highest, and that its value gradually decreases towards the base metal.

- The used transverse speeds has slight difference on the measured microhardness and it is found that the highest the transverse speed the highest the microhardness.

- The misrostructure was greatly affected as a result of being exposed to a large amount of plastic conformation, as the grains of the composite material transformed from large equiaxial grains in the base metal to large longitudinal granules in the area affected by the heat and then changed into small longitudinal granules in the area affected by the mechanical temperature and then finally small, homogeneous, equiaxial grains are obtained in the weld nugget region.

\section{ACKNOWLEDGMENT}

The author gratefully thanks the Deanship of Scientific Research at Taif University, Saudi Arabia, for financial support of this study via a research project no: 6119/439/1

\section{REFERENCES}

[1] Sahraeinejad S., Izadi H., Haghshenas M., and Gerlich A.P., "Fabrication of Metal Matrix Composites by Friction Stir Processing with Different Particles and Processing Parameters", Mater. Sci. Eng., A, 626, (2014), pp. 505-513

[2] Singla, M., Dwivedi, D.D., Singh, L., Chawla, V., "Development of Aluminum based Silicon Carbide Particulate Metal Matrix Composite", J Miner Mater Charact Eng 8(6): (2009), pp. 455-467

[3] Kamrani, S., Riedel R., Reihani S.M.S., Kleebe H.J., "Effect of Reinforcement Volume Fraction on the Mechanical Properties of Al-SiC Nanocomposites Produced by Mechanical Alloying and Consolidation", J Composite Materials, 44 (3), (2010), pp. 313-326

[4] Kady OE, Fathy A., "Effect of SiC particle size on the physical and mechanical properties of extruded $\mathrm{Al}$ matrix nanocomposites", Mater Des. 54, (2014), pp. 348-353.

[5] Rana R.S., Purohit R., Soni V. K., and Das S., "Characterization of Mechanical Properties and Microstructure of Aluminum Alloy-SiC Composites", Proc. of $4^{\text {th }}$ Int. Conf. on Mater Processing and Characterization, 2 (2015), pp. 1149 - 1156

[6] Reddy M.P., Shakoora R.A., Parande G., "Enhanced performance of nano-sized $\mathrm{SiC}$ reinforced $\mathrm{Al}$ metal matrix nanocomposites synthesized through microwave sintering and hot extrusion techniques", Prog. Nat. Sci. Mater. Int. 27 (5), (2017), pp. 606-614.

[7] Ahmadi A., Toroghinejad M.R., Najafizadeh A., "Evaluation of microstructure and mechanical properties of $\mathrm{Al} / \mathrm{Al}_{2} \mathrm{O}_{3} / \mathrm{SiC}$ hybrid composite fabricated by accumulative roll bonding process", Mater Des. 53, (2014), pp. 13-19.

[8] Murthy N.V., Reddy A.P., Selvaraj N, "Preparation of $\mathrm{SiC}$ based aluminum metal matrix nanocomposites by high intensity ultrasonic cavitation process and evaluation of mechanical and tribological properties", IOP Conf Ser Mater Sci Eng. (2016), 149:012106.

[9] Faisal N, Kumar K, "Mechanical and tribological behaviour of Nano-scaled silicon carbide reinforced aluminum composites", J of Exper. Nanoscience, Vol. 13, No. S1, (2018), pp. S1-S13

[10] Abo El-Nasr A.A., "Mechanical Properties and Fracture Behavior of Friction Stir Welded 7075-T6 Al Alloy", J Eng and Computer Sci, Qassim University, Vol. 3, No. 2, (July 2010), pp. 147-161

[11] D. Kumar, D.J. Ottarackal, U. Acharya, T. Medhi, B.S. Roy, S.C. Saha, "A Parametric Study of Friction Stir Welded AA6061/SiC AMC and Its Effect on Microstructure and Mechanical Properties", Mater Today: Proc., (2020), pp. 1-9

[12] M. El-Shennawy, A.A. Omar and M. Ayad, "Similar and Dissimilar Friction Stir Welding of AA7075", Intern J Mechanical Engineering (IJME), V. 3, Issue 4, July (2014), pp. 69-86

[13] Salih O.S., Ou H., Wei X., Sun W., "Microstructure and 
International Journal of Engineering Research and Technology. ISSN 0974-3154, Volume 13, Number 10 (2020), pp. 2973-2978

(C) International Research Publication House. https://dx.doi.org/10.37624/IJERT/13.10.2020.2973-2978

mechanical properties of friction stir welded AA6092/SiC metal matrix composite", Mater Sci. Eng., A 742 (2019), pp. 78-88

[14] Naresh P. and Kumar A., "Influence of Multi-hole Technique on Fabrication of Surface Nanocomposite by Friction Stir Processing, Advances in Manufacturing Processes", Sept. 11, (2018), pp. 555-571

[15] Paidar M., Asgari A. , Ojo O.O. , Saberi A., "Mechanical Properties and Wear Behavior of AA5182/WC Nanocomposite Fabricated by Friction Stir Welding at Different Tool Traverse Speeds", J Mater Eng. and Perform., V. 27, Issue 4, April (2018), pp. 1714-1724

[16] Prabhu S., Shettigar A.K., Rao K., Rao S., Herbert M., "Influence of Welding Process Parameters on Microstructure and Mechanical Properties of Friction Stir Welded Aluminum Matrix Composite", Mater Sci. Forum, Trans Tech Publ., (2017), pp. 50-53

[17] Wang Z., Song M., Sun C., "Effect of extrusion and particle volume fraction on the mechanical properties of $\mathrm{SiC}$ reinforced $\mathrm{Al}-\mathrm{Cu}$ alloy composites”, Mater Sci Eng A. 527, (2010), pp. 6537-6542.

[18] Fadavi Boostani AF, Tahamtan S, Jiang Z, "Enhanced tensile properties of aluminum matrix composites reinforced with graphene encapsulated $\mathrm{SiC}$ nanoparticles", Compos Pt A Appl Sci Manuf. 2015;68:155-163. S12 N. Faisal and k. Kumar

[19] Song J, Guo Q, Ouyang Q, "Influence of interfaces on the mechanical behavior of $\mathrm{SiC}$ particulate-reinforced Al-Zn-Mg-Cu composites", Mater Sci Eng A. 2015; 644: 79-84.

[20] https://www.nanoshel.com/sections/alloy-nano-powders].

[21] Inegbenebor A.O., Bolu C. A., Babalola P.O., Inegbenebor A.I., Fayomi O.I., "Aluminum Silicon Carbide Particulate Metal Matrix Composite Development Via Stir Casting Processing”, Silicon, 10, (2016), pp. 343-347

[22] S.V. Sujith, R.S. Mulik, "Thermal History Analysis and Structure-Property Validation of Friction Stir Welded Al-7079-TiC In-Situ Metal Matrix Composites", J. Alloys Compd. 812 (2020)

[23] U. Acharya, B.S. Roy, S.C. Saha, "On the Role of Tool Tilt Angle on Friction Stir Welding of Aluminum Matrix Composites", Silicon (2020), https://doi.org/10.1007/ s12633-020-00405-5

[24] Bodaghi M. and Dehghani K., "Friction Stir Welding of AA5052: "The Effects of SiC Nano-Particles Addition", Int. J. Adv. Manuf. Technol., 88 (9-12), (2016), pp. 2651-2660 